\title{
Flexible AC Transmission Systems (FACTS)
}

\author{
Therese Uzochukwuamaka Okeke and Ramy Georgious Zaher \\ University of Oviedo, Spain
}

\begin{abstract}
A setback arising from the pressure of increasing power transmission and distribution capacity could easily be resolved by expanding the network and/or installing more transmission lines. However, environmental and economic factors oppose the use of this resolution. These factors have engineered the onward research on designing power networks to provide maximum transmission capacity at minimum cost. The aftermath of the continuous research resulted in the use of Flexible $\mathrm{AC}$ Transmission Systems (FACTS), which is solely built on power electronics, to increase transmission capacity, improve stability \& dynamic behavior of the system and ensure better power quality. This paper will discuss basically the importance of FACTS in our networks, its components, the earliest technology used - Static VAR Compensator (SVC), and the most recent technology used Unified Power Flow Controller (UPFC).
\end{abstract}

Index Terms - Flexible AC Transmission Systems (FACTS), Unified Power Flow Controller (UPFC)

\section{INTRODUCTION - FLEXIBLE AC TRANSMISSION SYSTEMS}

STATIC and dynamic limits have been characterized in AC $\mathcal{N}$ transmission systems. These inherent limitations restrict power transmission, which leads to the under-utilization of existing transmission resources. Conventionally, mechanically switched shunt and series capacitors, reactors and synchronous generators were used to resolve much of the compounding problems. However, these conventional methods also encountered limitations, majorly: wear \& tear and slow response characteristics. The latter limitation brought solid state devices into limelight as an alternative technology for its fast response characteristic [1]. The need to use these devices further increased due to the rising nature of environmental and efficiency regulations. This alternative, together with the invention of Thyristor switch, is the foundation of power electronics devices in power systems, which is called Flexible AC Transmission Systems (FACTS). FACTS solutions are easily justified in applications requiring rapid dynamic response, ability for frequent variations in output, and/or smoothly adjustable output [2].

The development path from Thyristor based FACTS controllers to modern day voltage source converters (VSC) based FACTS controllers, was made possible due to rapid progressions in high power semiconductor devices.

\section{GENERAL BENEFITS OF FACTS}

A number of benefits can be attributed to the use of FACTS in power systems: They include:

a. Dynamic voltage control: Its main selling point is to limit over-voltages over lightly loaded lines and cable systems, and prevent voltage depressions or collapses in heavily loaded or faulty systems.

b. Increased power transmission capability and stability: Power networks can easily be stabilized without the need of installing new lines. This benefit is highly attractive because of cost reduction obtained from not installing new power lines. It also impacts on the environmental factors and restrictions placed on the complex expansion of networks.

c. Facilitation of renewable generation connection to the grid: Since FACTS has the characteristic of stability, renewable power generation could easily be connected to the grids with the aid of FACTS and thus fulfill the necessary grid code demands. [2]

These are the basic and most promising benefits associated with FACTS installations in power networks.

\section{FACTS EARLIEST TECHNOLOGY - SVC}

\section{A. Static VAR Compensator (SVC) \& its mode of operation}

SVC is the most primitive and first generation of FACTS controllers. It consists of a fast thyristor switch controlling a reactor and/or shunt capacitor bank (commonly called thyristor controlled reactors (TCR) and thyristor switched capacitors (TSC)), to provide dynamic shunt compensation, and/or harmonic filters - mechanically switched capacitors could be included. TCR generally consists of a fixed shunt reactor in series with a bi-directional thyristor valve. The reactors are air-core type, glass fibre insulated and epoxy resin impregnated. On the other hand, TSC consists of a capacitor bank in series with a bi-directional thyristor valve and a damping reactor which also serves to de-tune the circuit to avoid parallel resonance with the network. The thyristor 
switch present in TSC acts to connect or disconnect the capacitor bank for an integral number of half-cycles of the applied voltage. TSC is not phase controlled, which indicates the absence of harmonic distortion [3].

\section{B. SVC Characteristics}

An SVC has a VI characteristic as shown in Figure 1. Its current/susceptance is varied to regulate the voltage based on the droop or slope characteristics. This slope setting is critical in coordination with other voltage control equipment in the grid. It is also essential to determine at what voltage the SVC will reach its control range limit.

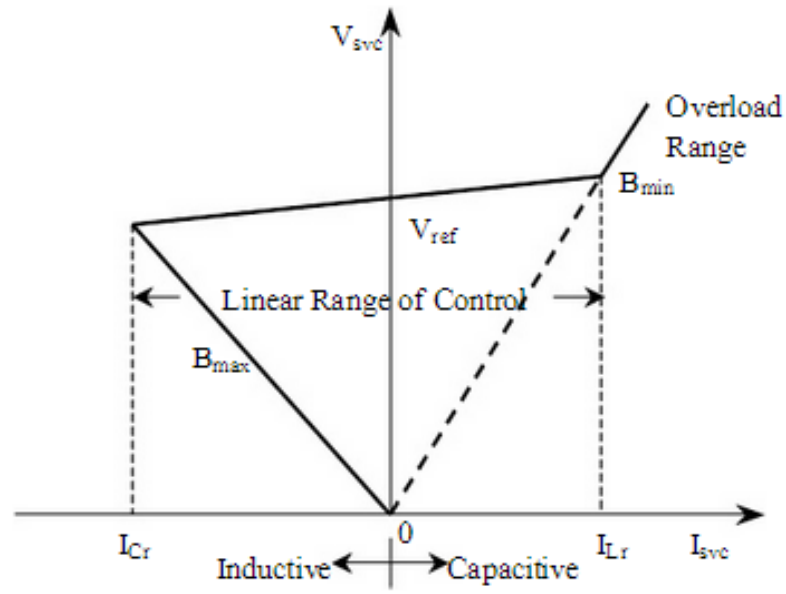

Figure 1. VI Characteristics of an SVC.

\section{SVC Control System}

The primary objective of the control system is to determine the SVC susceptance needed in the point of connection to the power system, in order to keep the system voltage close to the desired value. This function is realized by measuring the system voltage and comparing it with the reference value. When there is a discrepancy between the two values, the controller orders changes in the susceptance until equilibrium is attained. The controller operation results in a susceptance order from the voltage regulator which is converted into firing orders for each thyristor. The overall active SVC susceptance is given by the sum of susceptances of the harmonic filters, the continuously controllable TCR and/or TSC. The control system also includes supervision of currents and voltages in different branches [3].

\section{SVC Thyristor Valves}

Various types of thyristors, such as Phase Controlled or Bidirectional control thyristors are available for utilization in an SVC. For bi-directional types, it is designed to integrate two thyristors into one wafer with separate gate contacts, one for each current direction. Hence, the valves only require one thyristor stack in each phase instead of two, enabling considerable compacting of the valve design. TSR and TSC valves comprise a number of thyristors in series; this helps to obtain the voltage blocking capability needed for the valves.

\section{FACTS Most RECENT TECHNOLOGY - UPFC}

\section{A. Unified Power Flow Controller (UPFC) \& its mode of operation}

UPFC is one of the typical FACTS devices which can provide simultaneous control of all basic parameters of power system, which are transmission voltage, line impedance and phase angle. It also provides adequate compensation to the power system. The technology of UPFC is based on STATCOM and Static Synchronous Series Compensator (SSSC) principle, which means that it can adequately fulfill their functions. A basic structure of a UPFC consists of two voltage source converters (VSC); the first connected in parallel to the transmission line through a shunted transformer and the other, in series with the transmission line through a series connected transformer and connected together using a common dc link storage capacitor [4].

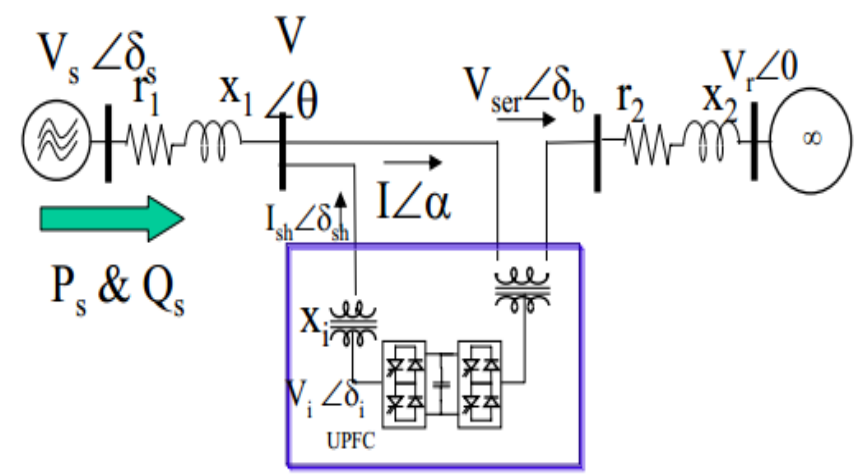

Figure 2. A schematic diagram showing a connected UPFC.

The main role of the shunt converter is to regulate voltage at DC link in order to inject the required reactive power flow into the line and to balance the active power flow exchanged between the series converter and the transmission line. Hence, the main function of UPFC is accomplished through the series converter. It acts as a voltage source and phase shift regulator. It controls active $\&$ reactive power flow by injecting adequate voltage with controllable magnitude and phase in series with the transmission line.

\section{B. UPFC Technology: STATCOM and SSSC}

a. STATCOM contribution to UPFC

The capability of STATCOM has been exploited in UPFC to control voltage and improve damping of the system.

STATCOMs are constructed in a similar way with a synchronous condenser but without inertia. Its characteristics entail better dynamics, lower investment, operating and maintenance costs. Its use of a voltage source converter, Gate Commutated Turn-off (GCT) thyristor gives it an improved structure and gate drive circuitry. This thyristor has drastically reduced the system operating losses due to the elimination of the snubber circuit.

This technology acts as the shunt connection of a UPFC, which is connected in parallel with the 
transmission line via a shunted transformer. As mentioned earlier, its main role is to regulate voltage at the DC link, just so that the required reactive power can be injected (by the SSSC).

\section{b. SSSC contribution to UPFC}

The SSSC technology is used as the series connection of a UPFC, which is connected in series with the transmission line through a coupling transformer. However, to utilize this connection in a UPFC, a source of energy is required for providing and maintaining the DC voltage across the DC capacitor seen in Figure 2 and compensation of SSSC losses. STATCOM acts as this source of energy needed by an SSSC, hence, leaving an SSSC with the responsibility of compensating reactive power [5].

\section{Possible UPFC Voltage Source Converters}

The VSCs used are forced-commutated power electronic devices, that is, GTOs, IGBTs or IGCTs, to synthesize a voltage from a DC voltage source. Two technologies are popularly used for VSCs and are [6]:

a. GTO-based square-wave converters and special interconnection transformers. It can normally be achieved by building four 3-level converters to obtain a 48-step voltage waveform. The special interconnection transformers are used to neutralize harmonics contained in the square waves generated by the individual converters. In this type of VSC, the fundamental voltage component is proportional to the DC voltage; hence, DC voltage is varied to control the injected voltage.

b. IGBT-based Pulse Width Modulation (PWM) converters. It utilizes PWM technique to artificially create a sinusoidal waveform from a DC voltage with a typical chopping frequency of some kilohertz. Harmonics in this type of converter are cancelled by connecting filters at the AC side of the converter. DC voltage used in this type of converter is fixed and its voltage is varied by changing the modulation index of the PWM modulator.

\section{SOME FACTS GLOBAL BREAKTHROUGH}

a. SVC was first installed in 1974 in Nebraska-USA by General Electric and in 1975 in Minnesota by Westinghouse Electric (now Siemens Power Generation Inc.)

b. Extra High Voltage (EHV) was first installed in 1984 (500kV NGH, SSR-Damping) in California by Siemens

c. TCSC (for load-flow control) was installed in Kayenta by Siemens d. STATCOM in 1995 in Sullivan-USA by Westinghouse Electric (now Siemens Power Generation Inc.)

e. The first breakthrough of UPFC occurred in 1998 with an installation carried out by American Electric Power (AEP), Westinghouse Electric (now Siemens Power Generation Inc.) and the Electric Power Research Institute (EPRI) at the Inez Station in Kentucky-USA [7, 8].

f. The world's largest SFC installed in 2001 in Richmond-USA by Siemens

g. The Convertible Static Compensator (CSC) was installed in 2001/2003 in Marcy-USA by Siemens [7].

\section{SUMMARY AND CONCLUSION}

We can conclusively say that power transmission facilities need to be developed at a corresponding pace with the rise of power demand. Among the driving forces of this development are - a rapid increase in inter-utility and inter-regional power transfer, demanding power corridors often of considerable lengths and of considerable power transmission capability, this in conjunction with the growing constraints on building new transmission lines due to economical and environmental considerations. Furthermore, deregulation has introduced additional requirements for flexibility in power systems for ensuring operational safety and stability under changing system conditions. Lastly, the growing impact of renewable energy supply (especially wind power) is placing new demands on the grid infrastructure, to ensure that the grid stability is maintained as its penetration increases.

FACTS have been proven useful from technical, economic and environmental points of view, to increase the utilization and stability of transmission systems. Its distinctive factor is the ability to provide reactive power for a variety of situations, thereby helping to maintain or even restore grids to stable operating conditions. The best attribute to this technology is its cost containment as compared to installing new transmission lines, plus the time factor attached to the installation.

The applicability of synchronous interconnection of grids has been widened to a significant amount with the invention of FACTS [2]. Limiting factors such as angular and voltage stability can be addressed in an efficient and cost-effective way. With a proper choice of devices from the FACTS family, optimum AC grid interconnection can be enabled, meaning that:

1. Power transmission capability as well as power availability can be increased and;

2. Transmission losses can be drastically reduced 
From an environmental point of view, FACTS enables the transmission of power over vast distances with less or much right-of-way impact than would otherwise be possible.

Continuous research on more dynamic FACTS devices will pave way to a highly efficient power system in times to come.

\section{REFERENCES}

[1] N. Acharya, A. Sode-Yome, N. Mithulanathan, "Facts about Flexible AC Transmission Systems (FACTS) Controllers: Practical Installations and Benefits"

[2] R. Grunbaum, A. Sannino, C. Wahlberg, "Use of FACTS for enhanced flexibility and efficiency in power transmission and distribution grids", ABB.

[3] R. Grunbaum, P. Andersson, (2012, 07,13), "FACTS-Intelligent Solutions for Meeting Challenges in Power Transmission"

[4] Y. Shu-jun, S. Xiao-yan, W. Yan, Y. Yu-xin, Y. Zhi, "Research on Dynamic Characteristics of Unified Power Flow Controller (UPFC)"

[5] A. Kazemi, S. Jamali, and H. Shateri, "Comparing Impacts of SSSC and STATCOM on Measured Impedance at Relaying Point", IEEE, 2009

[6] http://www.mathworks.com/help/physmod/powersys/ref/unifiedpowerfl owcontrollerphasortype.html

[7] C. Schauder, E. Stacey, M. Lund, L. Gyugyi, L. Kovalsky, A. Keri, A. Mehraban, A. Edris, "AEP UPFC project: Installation, Commissioning and Operation of the + 160 MVA STATCOM (phase I)", IEEE, October 1998, Volume 13, pp. 1530-1535

[8] http://www.ptd.siemens.de/Transmission_Development.pdf 